\title{
Un acercamiento a la moda desde la mirada filosófica de María Zambrano
}

\author{
An approach to fashion based on María Zambrano’s \\ philosophical perspective
}

$M^{a}$ ÁNGELES JIMÉNEZ HERRERA*

\begin{abstract}
Resumen: Este texto intenta dar respuesta desde la filosofía de María Zambrano al riesgo que supone que el individuo sometido a la moda, entendida como instrumento político y social de dominación, se externalice y se proyecte únicamente en su cuerpo, viviendo, de este modo, en el instante sin sentido. Frente a esta posibilidad Zambrano propone la necesidad de que la persona se enfrente a la nada como medio para recuperar su libertad y se adentre en su interioridad, de carácter temporal, para desde ahí construirse a partir del desarrollo de su propia esencia y de este modo trascenderse a sí misma.

Palabras clave: Zambrano, moda, efímero, interioridad, temporalidad, nada.
\end{abstract}

\begin{abstract}
Summary: This text is aimed at coping with the risk, considering María Zambrano's philosophy, caused by the fact that the individual subject to fashion, considered as a political and social instrument of domination, becomes superficial or soulless and projects himself/herself only on his/ her body, living, in this way, in the meaningless instant. Against this possibility, Zambrano proposes the need that the person faces the nothing as a means to regain his/her freedom and gets into his/her interiority, temporarily, so that it can build itself from there through the development of its own essence and so transcend itself.
\end{abstract}

Keywords: Zambrano, fashion, ephemeral, interiority, temporality, nothing.

No se puede concebir el concepto «moda» como una cuestión simplemente estética, sino que hay que plantearlo como un fenómeno pluridimensional que afecta a la sociedad en su conjunto, viéndose determinados por el mismo todos los ámbitos, tanto culturales, como políticos y sociales, tal y como lo han analizado autores como Gilles Lipovetski, John Carl Flügel, o Pierre Bourdieu1. De tal modo que podemos considerar la moda, más allá de un simple fenómeno sociológico de la sociedad contemporánea, como una consecuencia fundamental de las democracias en las que vivimos que permite dar cuenta del pensamiento y de la ideología

Fecha de recepción: 10/06/2016. Fecha de aceptación: 06/09/2016.

* Profesora de Enseñanza Secundaria en el I.E.S. Federico García Lorca. Máster en Filosofía Contemporánea por la Universidad de Granada y Doctora en Filosofía por la Universidad Autónoma de Madrid. Línea principal de investigación: pensamiento español. Dirección de correo electrónico: jimenezherrera79@hotmail.com.

1 Entre las obras que analizan estos temas desde distintos ámbitos destacamos: Lipovetsky, G. (2013), El imperio de lo efímero: la moda y su destino en las sociedades modernas, Barcelona: Anagrama; Flügel, J. C. (2015), Psicología del vestido, Madrid: Melusina; o Bourdieu, P. (2013), La distinción, Barcelona: Taurus. 
de nuestra época postmoderna. En esta línea afirma Adolfo Vásquez Rocca que «el tema de la moda lejos de ser un asunto meramente banal constituye un documento estético sociológico que da clara cuenta de las sensibilidades de una época, en particular de la voluntad de ruptura e innovación o, por otra parte, de férreo conservadurismo, quedando definido el asunto del vestir como un asunto sustancialmente político. La moda está en la calle y por lo tanto, es parte constitutiva de la res pública» ${ }^{2}$.

Así entendida, la moda debe distinguirse del arte, como dos órdenes separados. El arte supondría, en un sentido platónico, la plasmación de la belleza de carácter permanente y universal y la moda la constatación de lo transitorio, de la pura apariencia, en definitiva, de una estética «débil», siguiendo a Gianni Vattimo. Sin embargo, la sociedad contemporánea está asistiendo al fin del arte tal y como se ha entendido tradicionalmente. Muestra de ello es su mercantilización y su sometimiento a los cánones que impone la crítica, como mantiene Arthur C. Danto a lo largo de su obra Después del fin del arte ${ }^{3}$, lo que nos podría llevar a pensar que el arte ha sido subsumido por la propia moda.

Por otra parte, es innegable que la moda asume las características de la sociedad contemporánea en la que vivimos. Según Jean Baudrillard, la modernidad dota a la moda de sus propias características, es decir, lo efímero, lo fugitivo y lo contingente, creando, en definitiva, sujetos que buscan más la uniformidad que la diferenciación y en este sentido afirma «Como ya no es posible definirse por la propia existencia, sólo queda por hacer un acto de apariencia sin preocuparse por ser, ni siquiera por ser visto. Ya no: existo, estoy aquí; sino: soy visible, soy imagen -¡look, look!-. Ni siquiera narcisismo, sino una extroversión sin profundidad, una especie de ingenuidad publicitaria en la cual cada uno se convierte en empresario de su propia apariencia» ${ }^{4}$.

Esto daría lugar a considerar que la relación que se da entre moda e individuo se materializa en el propio cuerpo del individuo entendido como átomo social que se convierte en receptor de la moda, ya que en el sujeto se incorpora la tendencia estética predominante socialmente, utilizándola como definición de su rol social, status, etc. Así, Georg Simmel considera que el individuo utiliza la imitación como aprendizaje y al mismo tiempo, le permite mostrar su pertenencia al grupo social del que depende y con el que busca identificarse ${ }^{5}$. Del mismo modo, si la imitación es un rasgo esencial de la naturaleza humana, la moda es usada en las sociedades democráticas contemporáneas como un instrumento político y económico de dominación, ya que las distintas tendencias de la moda surgen en y para las clases más altas y cuando las demás clases acceden a ellas, la tendencias vuelven a cambiar, ya que su cometido es representar aquello exclusivo que se admira, se busca,

2 Vásquez Rocca, A. (2005), «La moda en la posmodernidad: deconstrucción del fenómeno fashion», NómadasRevista Crítica de Ciencias Sociales y Jurídicas (Madrid), nº 11, enero-junio 2005. [en línea], consultado el 10 de abril de 2015. URL:https:// http://www.ucm.es/info/nomadas/11/avrocca2.htm

3 Cf. Danto, A. (2010), Después del fin del arte, Barcelona: Paidós.

4 Cf. Baudrillard, J. (1990), La transparencia del mal, Anagrama: Barcelona, p. 29.

5 En relación a esta idea el autor define la moda como «imitación de un modelo dado que proporciona así satisfacción a la necesidad de apoyo social; conduce al individuo al mismo camino por el que todos transitan y facilita una pauta general que hace de la conducta de cada uno un mero ejemplo de ella. Pero no menos satisfacción da a la necesidad de distinguirse, a la tendencia a la diferenciación, a contrastar y destacarse», en Simmel, G. (1998), La aventura, Barcelona: Península, p. 101. 
o se desea. Por otra parte, lo medios de poder manipulan al individuo para hacerle creer que debe consumir un nuevo producto antes de que el que posee agote su funcionalidad.

Uno de los riesgos a los que están expuestos los individuos de las sociedades democráticas en las que impera la moda en todos los ámbitos es vivir proyectados en su cuerpo, externalizados de sí mismos y sometidos a los vaivenes que marca la dictadura de las tendencias, en un ahora inmediato y sin memoria. Peligro que puede ser analizado desde la crítica que hace Martin Heidegger a la existencia inauténtica o «das man», tipo de vida en la que el individuo no se responsabiliza de sus actos, vive en la trivialidad, en medio de una masa anónima que está guiada por el «se dice», «se piensa»...Un individuo que no se conoce a sí mismo y que, en definitiva, está perdido en el mundo proyectándose en la apariencia y al que se le impone desde los medios de comunicación y la publicidad qué es lo real y cómo debe ser asimilado ${ }^{6}$. Como afirma Lipovetsky, «los consumidores del siglo XXI, los hiperconsumidores, son seres incapaces de sobrellevar su propia existencia y tratan de aliviar todos sus males, especialmente la soledad, comprando» ${ }^{7}$. A lo que añadimos, comprando aquello que es dictado por los imperativos de la moda y asumiendo lo último como criterio de verdad.

Frente al riesgo que supone la externalización del individuo y su proyección únicamente en el cuerpo, a través de la imitación y la masificación, se hace necesario un movimiento contrario en el propio sujeto, una internalización que suponga la recuperación de la interioridad como lugar de constitución del propio individuo.

En este sentido, la filosofía de María Zambrano, que se inserta y asume una tradición de pensamiento que va desde los neoplatónicos, estoicos, San Agustín, Spinoza, entre otros, y que también conecta con otras corrientes como la mística sufí o el taoísmo, que han buscado la libertad y el rescate del individuo desde sí mismo, permite dar respuesta a los peligros en los que se encuentra atrapado el ciudadano del siglo XXI, el «hombre sin atributos» sometido a los imperativos de la moda que asume como propios, y que desdibuja, en definitiva, su propia identidad al proyectarse fuera de sí en aquella imagen impuesta por los dictados de la sociedad de consumo.

Zambrano propone como objeto de análisis filosófico a la persona individual, al ser humano considerado desde un punto de vista fenomenológico y no al hombre histórico que defiende Ortega y Gasset. Así afirma en Los sueños y el tiempo: «Pensar en función de la persona no puede ser reducir el conflicto haciéndolo entrar en otro sistema de conflicto. Es decir, pensar la historia, en sentido de pasado, desde otro sistema que sería igualmente del pasado, mas de otro pasado, lo cual agravaría el conflicto. Hay que pensar desde un punto fuera de toda historia, lo que a Ortega le parecería absolutamente inconcebible. Desde este punto ahistórico se abre una posibilidad, porque este punto situado en el vacío no puede ser cualquier punto, sino uno desde el cual la comunicación es posible. Un vacío cualitativo» ${ }^{8}$.

6 «La verdad de los medios de masas es pues la siguiente: cumplen la función de neutralizar el carácter vivido, único, de acontecimiento del mundo, para sustituirlo por un universo múltiple de medios homogéneos en su calidad de tales, que se significan recíprocamente y donde cada uno remite a los otros. Hasta el punto de que cada uno llega a ser el contenido recíproco de los demás y éste es el «mensaje» totalitario de una sociedad de consumo». Baudrillard, J. (2009), La sociedad de consumo: sus mitos y sus estructuras, Madrid: Siglo XXI, pp. 146.

7 http://www.jornada.unam.mx/2007/08/18/index.php?section=cultura\&article=a04n1 cul

8 Zambrano, M. (2011), Los sueños y el tiempo, en: Obras completas III. Libros (1955-1973), Barcelona: Galaxia Gutenberg-Círculo de lectores, p. 949. 
Zambrano plantea la necesidad de pensar la vida y la interioridad del individuo concreto que la vive. Desde el análisis que realiza del concepto de persona es posible dar respuesta al hombre histórico que surge como consecuencia de las sociedades de consumo en las que se encuentra inserto, sometido a la «moda plena» de la que nos habla Lipovetsky, es decir, a esos valores que lleva aparejados la propia moda y que convierten al individuo en un cuerpo sometido a la publicidad o a los valores hedonistas, a pesar de que, como defiende este autor, la moda suponga al mismo tiempo la constatación de la autonomía del sujeto en el pluralismo democrático 9 .

María Zambrano mantiene contra la filosofía existencialista, que somos seres creados, y a pesar de que estamos arrojados a la vida que tenemos que ir haciendo, nacemos con un ser que nos viene dado. Tenemos una esencia que se muestra en nuestra interioridad, la cual podemos libremente ir desarrollando o no. De este modo afirma que «El ser no es una pregunta, es una respuesta. Y en esta necesidad de ir que el hombre experimenta, lo que late, un tanto encubierta, es su trascendencia» ${ }^{10}$. Esta característica supone el hecho de que cada individuo es absolutamente diferente a otro, aunque al mismo tiempo comparte una realidad que le permite identificarse con lo heterogéneo que se muestra en las demás personas. Esta idea nos permite establecer una crítica a la idea de sujeto obediente a la moda, externalizado, convertido en cuerpo, máscara, que nos remite únicamente a lo puramente aparente desde un punto de vista estético, lo efímero y la construcción de individuos en serie sometidos al deseo de aquello que no son.

Frente al individuo, producto de las sociedades contemporáneas, que se desdibuja en el presente porque vive una realidad fragmentada, Zambrano afirma que el ser humano es un sujeto que se está haciendo en el tiempo, trascendiéndose a sí mismo y que no llega a ser completamente en el momento presente porque no termina de conocer su realidad, ya que le va siendo revelada de forma progresiva a través de lo que ella llama los «sucesivos despertares». En este sentido, para la filósofa la vida está haciéndose en el tiempo, en continuo cambio y el sujeto que la vive tiene una interioridad en la que debe refugiarse y ahondar porque es ahí donde fluye esa vida propia y donde la siente. Nos dice: «El hacer aparecer la realidad que le rodea es una función del ser hombre, la específica a lo que sabemos. Mas esa función es el cumplimiento de otra que la sostiene y subsiste bajo ella: el padecerla, y el serla. El tratar con la realidad humanamente es padecer sus ocultaciones. Y en cuanto a la "realidad" que es el hombre, el padecerla y padecerse en ella y desde ella -desde lo que ocultamente padece- es lo que se revela -la realidad objetiva- y lo que de sí mismo se actualiza y trasciende» ${ }^{11}$.

Zambrano quiere salvar la individualidad, aquello que es propiamente humano y que al mismo tiempo nos permite transcendernos. Es precisamente esa individualidad constitutiva del ser humano la que la dictadura de la moda hace desaparecer, ya que, como mantiene Baudrillard, «la moda es arbitraria, pasajera, cíclica y no añade nada a las cualidades intrínsecas del individuo» ${ }^{12}$. No podemos afirmarnos sólo como un ser que se ha externalizado, es decir, como un cuerpo en el que se plasman los vaivenes de la moda. Para la autora la interioridad del ser humano, que nos viene dada, es nuestro ser mismo. Por esta razón reivindica una persona que, por una parte, desarrolla su realidad desde lo que es, lo que íntimamente

9 Cf. Lipovetsky, G., El imperio de lo efímero: la moda y su destino en las sociedades modernas, op. cit., p. 336.

10 Zambrano, M. (2011), Notas de un método, Madrid: Tecnos, p. 99.

11 Zambrano, M., Los sueños y el tiempo, op. cit., pp. 864-865.

12 Baudrillard, J., La sociedad de consumo: sus mitos y sus estructuras, op. cit., p. 100. 
es, y por otra parte se enfrenta a la realidad externa, a la materia. El escenario donde se produce la dialéctica entre mi interioridad y la realidad exterior a la que me enfrento es la vida entendida como un proceso temporal. «La vida, en su condición de intermediaria entre lo que se presenta y el sujeto, aparece sin más. Lo que se presenta, que puede ser llamado, fenomenológicamente, materia -en cuanto que es dado por sí mismo con todos sus caracteres-. La vida y su fluir temporal está en medio» ${ }^{13}$.

El mundo es considerado por Zambrano, al igual que en Leibniz, como una unidad en la que toda la realidad está interrelacionada. El acceso a la misma se produce desde mi propia experiencia interior, desde el conocimiento de mi propia interioridad, es decir, mi propia alma, en la que la realidad se está dando, lugar en la que se está reflejando desde mis propias coordenadas. Al mismo tiempo todo lo que pasa permanece en la memoria, pero en una memoria vital y no de carácter histórico. Será en el tiempo, que se nos da en nuestra interioridad, donde el individuo se desarrolle, despliegue sus posibilidades, se mueva hacia la unión de vida y ser, guiado por la memoria y por la esperanza, como afirma en Notas de un método: «la existencia del sujeto, si bien se manifiesta en exaltación, está enraizada -no se trata de una simple metáfora- en los "ínferos" de la memoria, de la memoria misma y de aquello que está bajo ella, que tanto la sostiene como la agita, en ese fondo que se hunde si en él queremos parar mientes; las raíces o el fondo donde ellas se hunden, que acusa el peso que sostienen, el lugar de la gravitación del sujeto mismo y de todo peso que consigo porte. Un lugar que acusa porque siente, el punto de gravedad, es al par el punto donde sordamente yace el sentir originario, en el que el sujeto siente su propio peso, su propia condición» ${ }^{14}$.

En el mismo sentido, Henri Bergson, autor que influye profundamente en Zambrano, afirma que la distinción entre cuerpo y alma es temporal y no espacial, en oposición a la filosofía cartesiana. Para el filósofo el espíritu es el lugar que habita el pasado, mientras que el cuerpo es la morada del presente. Esto implica que tener consciencia de algún acontecimiento supone mirarlo e interpretarlo desde el mismo pasado. Por eso afirma que contentarse con la realidad que se da fuera del sujeto, reaccionar a estímulos externos, significa no ser consciente del hecho que acontece, sino dar una respuesta puramente corporal en la que no está implicada la identidad del individuo. El tomar conciencia de algo supone que mi interioridad interprete ese acontecimiento desde mis experiencias pasadas y a la luz de éstas dirija la acción hacia el futuro inmediato. La articulación temporal entre pasado, presente y futuro, y por tanto, la formación de mi propia identidad, sólo se puede realizar a través de la unión entre cuerpo y espíritu ${ }^{15}$. Si consideramos que la materia y la vida que conforman la realidad están también en nosotros, Bergson, al igual que Zambrano, apela al conocimiento interior. Adentrarnos en nosotros mismos y conocer nuestro espíritu mediante la intuición permite al mismo tiempo conocer la realidad ${ }^{16}$. Al igual que la realidad en la que estoy inmerso, mi alma está en constante devenir, sometida a la temporalidad. Por tanto, conocer mi alma implicará al mismo tiempo conocer la naturaleza de la realidad en la que me encuentro.

13 Zambrano, M., Los sueños y el tiempo, op. cit., p. 936.

14 Zambrano, M., Notas de un método,op. cit., p. 132.

15 Cf . Bergson, H. (1959), Materia y memoria, en: Obras completas, México: Aguilar, pp. 274- 279.

16 Cf. Bergson, H. (2013), «La intuición filosófica», en: El pensamiento y lo moviente, Buenos Aires: Cactus, p. 141 . 
Desde estas filosofías que reivindican la interioridad humana de carácter temporal como signo de identidad del yo, no puede ser aceptable un concepto de sujeto reducido al cuerpo, que esté sometido a estructuras externas a sí mismo, como, en este caso, por la moda. Así la «moda plena» como característica propia de las ideologías contemporáneas que fomentan el cambio, la movilidad frívola y lo efímero como eje permanente de nuestra movilidad histórica, conlleva la desaparición del concepto de libertad y de interioridad, en definitiva, de persona que se desarrolla en el tiempo, reivindicado por estos autores, para dar paso a un sujeto que se caracteriza por un desarrollo libertario de una personalidad impuesta por las tendencias de la moda y el hedonismo vacío propio de una sociedad basada en la lógica del consumo, tal y como afirma Lipovetsky.

Sin embargo, para Zambrano vivir implica que la persona se desarrolle en función de lo que es, de lo que tiene en sí y que se despliegue en el tiempo gracias al deseo de lo otro, el deseo de trascenderse. Lo propiamente humano surge desde el misterio del ser, del sentir originario de lo insondable de la realidad que sólo puede ser captado por la intuición dentro de mi propia interioridad.

En este sentido, y frente a posturas como la de Baudrillard que afirma que no hay salida para el individuo en la sociedad de consumo $^{17}$, la recuperación del mismo puede venir paradójicamente de la experiencia de la nada dentro de esta sociedad del hiperconsumo y la apariencia. «La nada asemeja ser la sombra de un todo que no accede a ser discernido, el vacío de un lleno tan compacto que es su equivalente, la negativa muda informulada a toda revelación. Es lo sagrado "puro" sin indicio alguno de que permitirá ser develado» ${ }^{18}$.

Zambrano dará especial importancia al hecho de que en la experiencia de la realidad el ser humano sienta la realidad que le sobrecoge. Por lo que la nada, que no puede ser apresada por el concepto o la imagen, porque no hay ser que delimitar, sí puede ser padecida, y esta experiencia se nos presenta como incuestionable. Para la autora de Claros del bosque, el individuo contemporáneo no quiere aceptar el hecho de que se le revele como experiencia algo que sobrepasa los límites de la razón impuesta por la sociedad dominante. Sin embargo, la nada como experiencia de lo absoluto imposible de ser conceptualizado se impone. «La nada es lo irreductible que encuentra la libertad humana cuando pretende ser absoluta. Y la pretensión de algo absoluto sobre aquello que se le resiste, verificándose así una conversión entre lo absoluto del ser y del no-ser. Quien pretende ser absolutamente acaba sintiéndose nada dentro de una resistencia sin fronteras. Es lo sagrado que reaparece en su máxima resistencia. Lo sagrado con todos sus caracteres: hermético, ambiguo, activo, incoercible ${ }^{19}$. Para María Zambrano la experiencia de la nada en la sociedad contemporánea se concibe al margen de Dios, «aparece la nada rodeando el proyecto de ser, la inexorable exigencia de existir, no vencida por ella, ni vencedora. El tiempo es la única victoria del existente» ${ }^{20}$.

17 En este sentido afirma el autor que todo lo que puede hacer el individuo en la sociedad de consumo es «vivir el consumo como una especie de seductora enfermedad terminal», Baudrillard, J., La sociedad de consumo: sus mitos y sus estructuras, op. cit., p. LIII.

18 Zambrano, M. (2011), El hombre y lo divino, en: Obras completas III. Libros (1955-1973), Barcelona, Galaxia Gutenberg-Círculo de lectores, p. 218.

19 Ibíd., p. 217.

20 Ibíd., p. 212. 
Sin embargo, para Zambrano, la aparición de la nada, última manifestación de lo sagrado como no-ser (concibiendo sagrado como realidad misteriosa que nos desborda), se presenta al hombre contemporáneo con una función liberadora ya que conduce a la persona más allá del instante mismo en el que se encuentra inserto en el que la libertad es mera apariencia bajo los dictados del consumo y la moda ${ }^{21}$. Así, la experiencia de la nada no debe implicar quedarse en la nada misma. No significa quedarse en la constatación del absurdo de una existencia sin sentido, porque la nada es al mismo tiempo que no-ser, posibilidad de recuperación del ser humano a través del movimiento de la trascendencia que supone que el individuo pueda salir de la cárcel solipsista que paradójicamente él mismo se ha construido en la sociedad contemporánea del mundo de la imagen vacía y del imperio de lo efímero. La nada se presenta como resistencia, pero al mismo tiempo como elemento activo que va a permitir que la persona se desposea para que se pueda dar el encuentro con lo otro de la realidad. Para Heidegger, al igual que para María Zambrano, la experiencia de la nada posibilitará la constatación del ente mismo: «Sólo en la clara noche de la nada de la angustia surge por fin la originaria apertura de lo ente como tal: que es ente y no nada. [...] La esencia de la nada cuyo carácter originario es desistir reside en que ella es la que conduce por vez primera al ser aquí ante lo ente como tal» ${ }^{22}$.

Así, la necesidad de recuperar un conocimiento de lo que es propio de cada persona, una interioridad de carácter espiritual, que nos distinga del otro y que al mismo tiempo nos acerque a él a través del encuentro con la nada, se convierte en una propuesta para recuperar la libertad del yo, sustrayéndonos de este modo de los imperativos de la moda y la sociedad de consumo que convierten a los seres humanos en «cuerpos dóciles», productivos, analizables, manipulables y sometidos, en un sentido foucaultiano ${ }^{23}$.

\section{Bibliografía citada}

Baudrillard, Jean (1990): La transparencia del mal, Anagrama, Barcelona.

Baudrillard, Jean (2009): La sociedad de consumo: sus mitos y sus estructuras, Siglo XXI, Madrid.

Bergson, Henri (1959): Materia y memoria, en Id., Obras completas, Aguilar, México.

Bergson, Henri (2013): «La intuición filosófica», en Id., El pensamiento y lo moviente, Cactus, Buenos Aires.

Bourdieu, Pierre (2013): La distinción, Taurus, Barcelona.

Danto, Arthur (2010): Después del fin del arte, Paidós, Barcelona.

Flügel, John Carl (2015): Psicología del vestido, Melusina, Madrid.

Foucault, Michael (2012): Vigilar y castigar, Siglo XXI, Madrid.

Heidegger, Martin (2003): ¿Qué es metafísica?, Alianza, Madrid.

21 «El consumidor vive sus conductas distintivas como libertad, como aspiración, como elección y no como imposiciones de diferenciación ni como obediencia a un código [...] no vive la presión estructural que hace que las posiciones se intercambien y el orden de las diferencias se perpetúe». Baudrillard, J., La sociedad de consumo: sus mitos y sus estructuras, op. cit., p. 56.

22 Heidegger, M. (2003), ¿Qué es metafísica?, Madrid: Alianza, p. 31.

23 Cf. Foucault, M. (2012), Vigilar y castigar, Madrid: Siglo XXI, pp. 157-198. 
Lipovetsky, Gilles (2013): El imperio de lo efímero: la moda y su destino en las sociedades modernas, Anagrama, Barcelona.

Simmel, Georg (1998): La aventura, Península, Barcelona.

Vásquez Rocca, Adolfo (2005): «La moda en la posmodernidad: deconstrucción del fenómeno fashion», Nómadas-Revista Crítica de Ciencias Sociales y Jurídicas (Madrid), ${ }^{\circ}$ 11, enero-junio 2005.

Zambrano, María (2011): El hombre y lo divino, en Id., Obras completas III. Libros (19551973), Galaxia Gutenberg-Círculo de lectores, Barcelona.

Zambrano, María (2011): Los sueños y el tiempo, en Id., Obras completas III. Libros (19551973), Galaxia Gutenberg-Círculo de lectores, Barcelona.

Zambrano, María (2011): Notas de un método, Tecnos, Madrid. 